\section{Nestin expression associates with poor prognosis and triple negative phenotype in locally advanced (T4) breast cancer}

\author{
F. Piras, ${ }^{1}$ M.T. Ionta, ${ }^{2}$ S. Lai, ${ }^{1}$ M.T. Perra, ${ }^{1}$ \\ F. Atzori, ${ }^{2}$ L. Minerba, ${ }^{3}$ V. Pusceddu, ${ }^{2}$ \\ C. Maxia, ${ }^{1}$ D. Murtas, ${ }^{1}$ P. Demurtas, ${ }^{1}$ \\ B. Massidda, ${ }^{2}$ P. Sirigu ${ }^{1}$ \\ 'Department of Cytomorphology, \\ University of Cagliari; ${ }^{2}$ Department of \\ Medical Oncology, University of Cagliari; \\ ${ }^{3}$ Department of Public Health, University \\ of Cagliari, Italy
}

\section{Abstract}

Nestin, an intermediate filament protein has traditionally been noted for its importance as a neural stem cell marker. However, in recent years, expression of nestin has shown to be associated with general proliferation of progenitor cell populations within neoplasms. There is no reported study addressing nestin expression in T4 breast cancer patients. Thus, the aim of the present study was to investigate, through immunohistochemistry, the expression and distribution of nestin in T4 breast cancer, in order to determine its association with clinical and pathological parameters as well as with patients' outcome. Nestin was detectable in tumoral cells and in endothelial cells of blood microvessels, and it is significantly expressed in triple-negative and in inflammatory breast cancer (IBC) subgroups of T4 breast tumours. The Kaplan-Meier analysis showed that the presence of nestin in tumoral cells significantly predicted poor prognosis at 5 -years survival $(\mathrm{P}=0.02)$ and with borderline significance at 10 -years of survival $(\mathrm{P}=0.05)$ in $\mathrm{T} 4$ breast cancer patients. On the basis of these observations, we speculate that nestin expression may characterize tumours with an aggressive clinical behavior, suggesting that the presence of nestin in tumoral cells and vessels may be considered an important factor that leads to a poor prognosis. Further studies are awaited to define the biological role of nestin in the etiology of these subgroups of breast cancers.

\section{Introduction}

Among all the potentially useful prognostic biomarkers, the International Union Against Cancer (UICC)/American Joint Committee on
Cancer (AJCC) TNM staging system, ${ }^{1}$ incorporates only tumor thickness, nodal status, and presence of distant metastase because, in the most of the other clinicopathologic prognostic factors, there aren't reproducible definitions, easy applicable, and they are lacking of agreement among the world's experts. According to this system, primary breast cancers with extension to the skin are classified as T4, and patients with T4 carcinomas of any type, with or without lymph node involvement, and without distant metastases (T4 N0-2 M0), are classified as disease stage IIIB. Primary breast carcinomas infiltrating skin or chest wall (T4 ac), as well as inflammatory breast carcinoma (T4d, IBC), are included in locally advanced breast cancer (LABC) group. ${ }^{1,2}$ In addition to the tumour size and the axillary lymph node involvement, other well-established prognostic factors currently used in breast cancer include histological subtype or grade, estrogen (ER) and progesterone (PR) receptor status, HER2 amplification, and Ki67 proliferation index. ${ }^{3,4}$ LABC remains a clinical challenge as the majority of patients with this diagnosis develop distant metastases despite appropriate therapy. ${ }^{5}$ The molecular mechanisms underlying $\mathrm{LABC}$ are largely unknown. Identification of these may contribute to develop new therapies that can arrest local invasion and metastatic spread of the disease.

Nestin, an intermediate filament protein, has traditionally been noted for its importance as a neural stem cell marker. ${ }^{6,7}$ However, in recent years, expression of nestin has shown to be associated with general proliferation of progenitor cell populations within neoplasms. Several studies have thus targeted nestin as a potential diagnostic and prognostic marker of brain malignancy.,9 Upregulation of nestin is also closely associated with malignancy and metastasis of other types of cancer outside of the brain such as melanoma, ${ }^{10}$ colorectal, ${ }^{11}$ prostate, ${ }^{12}$ and pancreatic cancer. ${ }^{13}$ In breast cancer, nestin expression was evaluated in T1, $\mathrm{T} 2$, and $\mathrm{T} 3$ breast carcinomas ${ }^{14-18}$ and was found preferentially in triple negative and basal like phenotype of these tumours. These findings substantiate the possibility of using nestin as a marker for triple-negative phenotype of $\mathrm{T} 1, \mathrm{~T} 2$, and $\mathrm{T} 3$ breast carcinomas but, currently, there is no reported study addressing nestin expression in T4 breast cancer patients.

A distinct gene-expression profile has been described for $\mathrm{T} 3 / \mathrm{T} 4$ tumours in comparison to the gene-expression pattern of $\mathrm{T} 1 / \mathrm{T} 2$ tumours, ${ }^{19}$ suggesting that a distinct biological behaviour may characterize initial vs. locally advanced breast carcinomas. ${ }^{20,21}$

In the light of these findings, in the present study we examined the expression of nestin in a well-characterized cohort of patients with $\mathrm{T} 4$
Correspondence: Franca Piras, Department of Cytomorphology, University of Cagliari, Cittadella Universitaria, 09042 Monserrato (CA), Italy. Tel. +39.070 .6754004 - Fax: +39.070 .6754003 . E-mail: fpiras@unica.it

Key words: Nestin, T4 breast cancer, triple negative, prognosis.

Acknowledgements: the authors are grateful to patients for their important contribution to this study. Particular thanks are due to Mrs. Itala Mosso and Mr. Massimo Annis for their expert technical assistance.

Contributions: FP and MTI contributed equally to the manuscript.

Received for publication: 27 July 2011. Accepted for publication: 13 September 2011.

This work is licensed under a Creative Commons Attribution NonCommercial 3.0 License (CC BYNC 3.0).

(C) Copyright F. Piras et al., 2011

Licensee PAGEPress, Italy

European Journal of Histochemistry 2011; 55:e39 doi:10.4081/ejh.2011.e39

breast carcinoma and a long follow-up, in order to determine its association with clinical and pathological parameters as well as with patients' outcome.

\section{Materials and Methods}

\section{Patients and tissue specimens}

Paraffin-embedded samples of 53 patients with $\mathrm{T} 4$ breast cancer were included into the study. Cases were enrolled between 1992 and 2001, and observed up to September 2008 for a median of 125 months (range, 82-194). Patients were assessed by physical examination and mammography, confirmed via coreneedle biopsy. Of 13 patients both core-needle biopsy and surgical specimen were available. All patients completed a treatment plan including primary chemotherapy, surgery, radiation therapy, adjuvant chemotherapy, and hormone therapy, when indicated (see below). The median age was 51 years (range, 32-67). Baseline characteristics are summarized in Table 1. According to the American Joint Committee on Cancer (AJCC) TNM staging system, ${ }^{1}$ all 53 cases included into this study were classified with the highest stage of nonmetastatic disease (Stage IIIB). Estrogen (ER) and progesterone (PR) status was assessed by standard immunohistochemistry; nuclear staining in $\geq 10 \%$ was considered positive 
(according to the indication that a significant difference in 5 -year recurrence-free surviva between ER-positive and ER-negative patients has been reported for a cut-off of 10\%). ${ }^{22}$ HER2 status was assessed by fluorescence in situ hybridization (FISH) analysis. The study was approved by the Institutional Review Board at the University of Cagliari. A written informed consent was obtained for using tissue specimens in molecular analyses.

\section{Treatment plan}

All patients were treated with primary chemotherapy using anthraceyline-containing regimens, such as FEC (5-Fluorouracil; Epirubicin; Cyclophosphamide) or PEV (Cisplatin; Epirubicin; Vinorelbine). After completing the neoadjuvant chemotherapy, patients underwent surgery consisting of modified radical mastectomy (MRM) or breast-conserving surgery (BCT). Postoperative adjuvant chemotherapy consisted of six cycles of CMF (cyclophosphamide, methotrexate, fluorouracil). Locoregional radiotherapy was performed during the fourth course of CMF. After completing adjuvant chemotherapy, patients with hormone receptor-positive tumours received tamoxifen for 5 years. Clinical evaluations were performed every 3 months for 2 years and every 6 months thereafter. Instrumental examinations (e.g., mammography, liver ultrasound, chest X-ray, bone scan, and echocardiogram) were performed every 6 months for the first 2 years, and every 12 months thereafter.

\section{Response assessment}

The clinical measurement of the response to neoadjuvant therapy was defined according to the International Union Against Cancer (UICC) criteria. ${ }^{23}$ Pathological complete response (pCR) was defined as the histological absence of residual invasive disease in both the breast and the axilla. Presence of histological invasive residual disease in breast tissue or detection of cancer-positive lymph nodes in the axilla were defined as $<\mathrm{pCR}$. Major pathological response $(\mathrm{MpR})$ in breast tissue was defined as no more than $2 \mathrm{~cm}$ of residual disease (pT0 plus pT1). ${ }^{24}$

\section{Immunohistochemistry}

Serial microtome sections, $5 \mu \mathrm{m}$ thick, were treated immunohistochemically for nestin antigen, and for endothelial cell marker CD31 using the alkaline phosphatase-streptavidin method. Heat-induced antigen retrieval was performed at $95^{\circ} \mathrm{C}$ for $40 \mathrm{~min}$ in $10 \mathrm{mM}$ citrate buffer solution ( $\mathrm{pH}$ 6.0), for CD31. No antigen retrieval was used for nestin immunostaining. Non-specific binding was blocked with $10 \%$ normal goat serum for nestin immunostain- ing, or with normal horse serum for CD31 immunostaining, for $45 \mathrm{~min}$. Mouse monoclonal antibodies against nestin (Novus Biologicals, Littleton, CO, USA; clone 10C2; 1:500 dilution), and mouse monoclonal antibodies to human CD31 (Dako, Glostrup, Denmark; clone JC70A; 1:50 dilution) were used as primary antisera. Alkaline phosphatase (AP) conjugated anti-mouse antibodies (Chemicon Int., Temecula, CA, USA; 1:200 dilution) were used as secondary antisera in nestin immunostaining. Biotinylated antimouse IgG were used as secondary antisera (Vector Laboratories, Burlingame, CA, USA; 1:1000 dilution) for CD31 immunostaining, and the sections were further incubated in alkaline phosphatase-streptavidin (Vector Laboratories, 1:1000 dilution). Liquid Permanent Red (LPR) substrate-chromogen system (Dako) was used to develop the APase reaction product. Negative controls were established by replacing the primary antibod- ies with normal serum. Melanoma specimen, which strongly expressed nestin was used as positive control for nestin immunostaining.

To confirm that nestin positive microvessels were blood vessels, nestin and CD31 immunostaining were performed using serial tissue sections.

Slides were viewed using microscope Zeiss Axiophot (Carl Zeiss Inc., Oberkochen, Germany). The entire tumor of each case was microscopically examined through $200 \mathrm{X}$ magnification fields with a 144-intersection point square reticulum $\left(0.78 \mathrm{~mm}^{2}\right)$ inserted in the eyepiece to count nestin immunoreactive cells of whole tumor, and the average of this counts was considered. Nestin expression was evaluated by three of the authors (FP, SL, PS) according to the following criteria: cases with $<10 \%$ of discrete cytoplasmic expression in morphologically unequivocal neoplastic cells were classified as negative and cases with $\geq 10 \%$ of discrete cytoplasmic expression in

Table 1. Tumor characteristics and clinical variables: association with nestin expression and with overall survival.

\begin{tabular}{|c|c|c|c|c|c|}
\hline & N. of patients & Nestin & P* & N. of events & $\mathrm{P}^{\circ}$ \\
\hline $\begin{array}{l}\text { Age } \\
\qquad 51^{\sharp} \\
>51\end{array}$ & $\begin{array}{l}25 \\
28\end{array}$ & $\begin{array}{l}11 \\
17\end{array}$ & 0.276 & $\begin{array}{l}15 \\
15\end{array}$ & 0.541 \\
\hline $\begin{array}{l}\text { Tumor stage } \\
\text { T4abc } \\
\text { T4d }\end{array}$ & $\begin{array}{l}38 \\
15 \\
\end{array}$ & $\begin{array}{l}16 \\
12 \\
\end{array}$ & 0.016 & $\begin{array}{c}21 \\
9\end{array}$ & 0.455 \\
\hline $\begin{array}{l}\text { Axillary nodes } \\
\text { cLN } 0 \\
\text { cLN }+\end{array}$ & $\begin{array}{l}12 \\
41\end{array}$ & $\begin{array}{c}6 \\
22\end{array}$ & 1.000 & $\begin{array}{c}3 \\
27\end{array}$ & 0.029 \\
\hline $\begin{array}{l}\text { Triple negative } \\
\text { Yes } \\
\text { No }\end{array}$ & $\begin{array}{l}18 \\
35\end{array}$ & $\begin{array}{l}15 \\
13 \\
\end{array}$ & 0.002 & $\begin{array}{l}13 \\
17\end{array}$ & 0.039 \\
\hline $\begin{array}{l}\text { Hormone receptor status } \\
\text { ER - PR- } \\
\text { ER }-\mathrm{PR}+ \\
\text { ER }+\mathrm{PR}- \\
\mathrm{ER}+\mathrm{PR}+\end{array}$ & $\begin{array}{c}24 \\
1 \\
12 \\
16\end{array}$ & $\begin{array}{c}17 \\
1 \\
6 \\
4\end{array}$ & 0.029 & $\begin{array}{l}16 \\
0 \\
6 \\
8\end{array}$ & 0.140 \\
\hline $\begin{array}{l}\text { Estrogen receptor status } \\
\text { ER+ } \\
\text { ER - }\end{array}$ & $\begin{array}{l}28 \\
25\end{array}$ & $\begin{array}{l}10 \\
18\end{array}$ & 0.013 & $\begin{array}{l}14 \\
16\end{array}$ & 0.075 \\
\hline $\begin{array}{l}\text { Progesteron receptor status } \\
\text { PR }+ \\
\text { PR - }\end{array}$ & $\begin{array}{l}17 \\
36\end{array}$ & $\begin{array}{c}5 \\
23\end{array}$ & 0.037 & $\begin{array}{c}8 \\
22\end{array}$ & 0.079 \\
\hline $\begin{array}{l}\text { HER2 status } \\
\text { HER2 + } \\
\text { HER2 - }\end{array}$ & $\begin{array}{l}10 \\
43\end{array}$ & $\begin{array}{c}3 \\
25\end{array}$ & 0.162 & $\begin{array}{c}5 \\
25\end{array}$ & 0.635 \\
\hline $\begin{array}{l}\text { Grading } \\
\text { G2 } \\
\text { G3 }\end{array}$ & $\begin{array}{l}38 \\
15\end{array}$ & $\begin{array}{c}22 \\
6\end{array}$ & 0.360 & $\begin{array}{c}23 \\
7\end{array}$ & 0.461 \\
\hline $\begin{array}{l}\text { Pathological response } \\
\text { pCR } \\
<\mathrm{pCR}\end{array}$ & $\begin{array}{c}8 \\
45\end{array}$ & $\begin{array}{c}5 \\
23 \\
\end{array}$ & 0.255 & $\begin{array}{c}2 \\
28 \\
\end{array}$ & 0.087 \\
\hline $\begin{array}{l}\text { Clinical response } \\
\text { Complete response } \\
\text { Partial response } \\
\text { < Partial response } \\
\end{array}$ & $\begin{array}{c}8 \\
36 \\
9\end{array}$ & $\begin{array}{c}4 \\
17 \\
7 \\
\end{array}$ & 0.256 & $\begin{array}{c}2 \\
20 \\
8\end{array}$ & 0.043 \\
\hline
\end{tabular}

*Fisher's exact test or Pearson's test; ${ }^{\circ}$ log-rank test; " $m e d i a n$ age; ${ }^{\circledR}$ after primary chemotherapy. 
morphologically unequivocal neoplastic cells were considered to be positive.

\section{Statistical analysis}

Pearson's and Fisher's exact tests were used to evaluate possible associations between covariates such as nestin expression, ER, PR, HER2 and clinical outcome in terms of treatment responses, and to evaluate a correlation of nestin expression with clinicopathological variables as age, grading, axillary lymph node metastasis, hormon receptor status, and HER2 status. Univariate correlations between prognostic variables and overall survival were carried out using the Kaplan-Meier method. Comparisons were made using the log-rank test. Overall patient survival rates were calculated from the date of initial primary chemotherapy to the date of death caused by breast cancer, or last follow-up, until September 2008. Data on patients who died of other causes were censored at the time of death. Statistical comparisons were performed using the SPSS Statistical Package for Social Science, version 15.0 (SPSS Inc., Chicago, IL, USA). All tests were two-tailed and $P$ values of less than 0.05 were considered to be statistically significant.

\section{Results}

\section{Immunohistochemistry}

Nestin was expressed in a wide variety of cells, including tumor cells, endothelial cells of blood microvessels, basal cells of apparently normal mammary glands, and in cells with fibroblast morphology in the peritumoral stroma (Figure 1), especially surrounding both ductus and vessels. CD31 expression was found in vascular endothelial cells and in scattered cells of all cases.

When nestin expression was detected at the periphery of ducts or/and in vessels, or/and in peritumoral stroma, but not in the tumor itself, the tumors were scored as negative. Positivity for nestin was defined as detectable expression within the tumor and not merely at the periphery of the tumor. For example, a carcinoma in which the intact basal/myoepithelial layer stains positive but the cells within the core of the carcinoma do not, would be scored as negative. The tumors were scored as positive only when nestin expression was detected in tumor cells.

\section{Statistical analysis}

Cases with more than $10 \%$ of tumor cells positive for nestin included $53 \%$ of cases examined. All cases showed nestin expression in scattered cells and in endothelial cells of microvessels. Seventy percent of cases showed nestin expression in cells with fibroblasts morphology. No change in expression of nestin was found between core-needle biopsies and surgical specimens in the 13 cases for which both samples were available.

Using Pearson's and Fisher's exact tests, nestin expression was evaluated for association with histological tumour characteristics and/or with clinical variables (Table 1). Statistical difference was found in nestin expression between inflammatory and non inflammatory group of patients $(\mathrm{P}=0.016)$. Among patients who had initially inflammatory breast carcinoma (T4d), 80\% were nestin positive. Nestin was mostly expressed in triple negative tumours respect to those no triple negative. Results indicate that in $83 \%$ of triple-
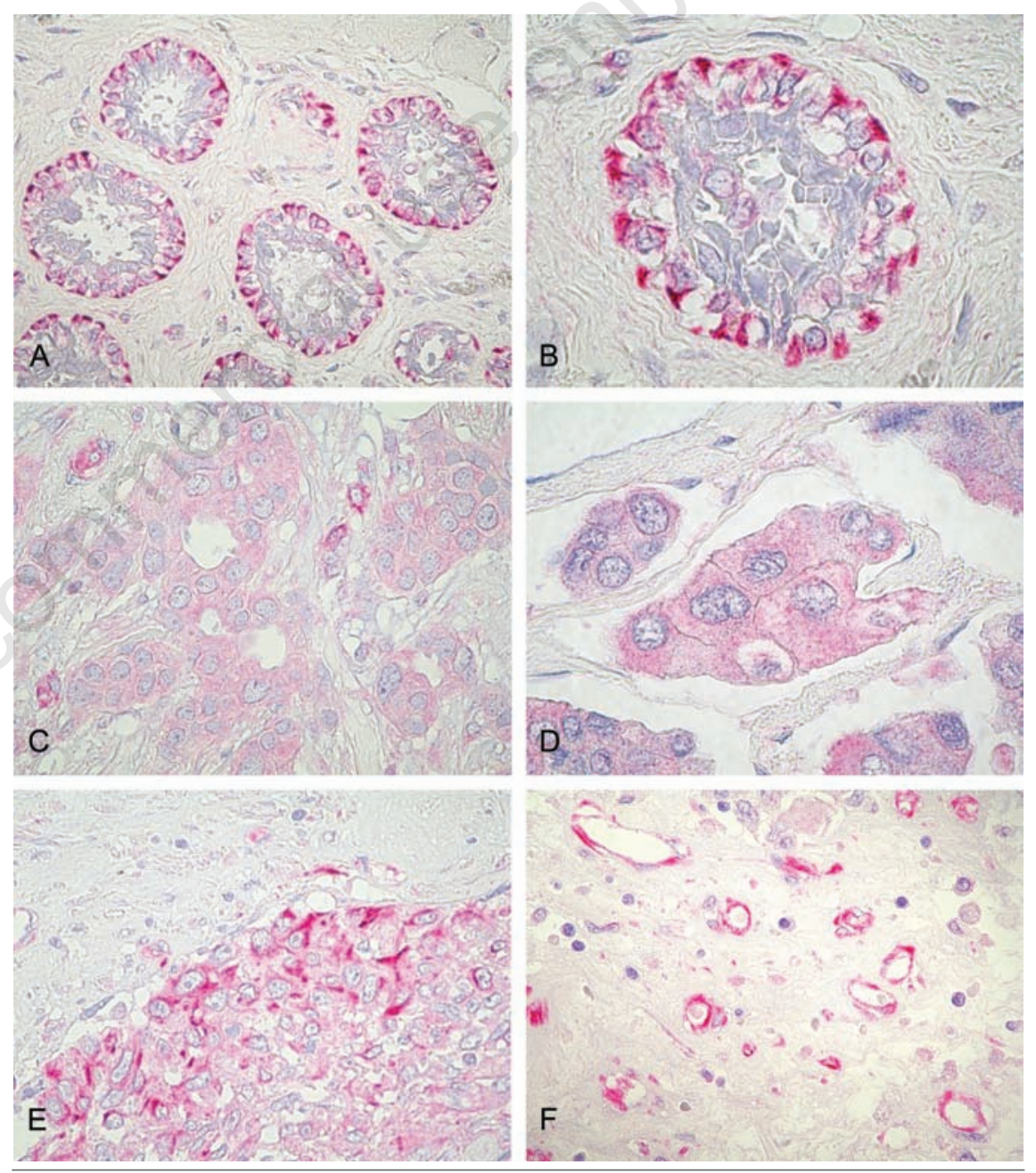

Figure 1. Immunohistochemical staining of nestin in breast cancer. A,B) nestinimmunoreactivity was found in myoepithelium of the apparently normal mammary glands adiacently to tumoral mass (internal positive control); C), presence of cytoplasmic nestin expression in tumoral cells of a T4b breast cancer case with ER+, PgR+, HER2phenotype. D), presence of nestin expression in tumoral cells of a T4d inflammatory breast cancer case with ER+, PgR-, HER2- phenotype; E), presence of nestin expression in tumoral cells of aT4d inflammatory breast cancer case with ER-, PgR-, HER2- triple-negative phenotype. F), intense nestin immunoreactivity in endothelial cells of peritumoral stroma. Original magnification: x400 (A); x1000 (B, D); x630 (C, E, F). 
correlation between tumoral cells nestin expression and stromal cells with fibroblast morphology nestin expression was observed $(\mathrm{P}=1)$. Particularly, stromal nestin expression was found in 12 of 18 triple negative cases (67\%) and in 8 of 15 inflammatory breast cancer cases (53\%). No statistical association was found between stromal nestin expression and triple negative phenotype $(\mathrm{P}=0.77)$ or inflammatory breast cancer $(\mathrm{P}=0.53)$.

In the same table is also observable that, among clinicopathological factors, only nodal involvement, triple negative status, and clinical response to primary chemotherapy significantly correlated with survival $(\mathrm{P}<0.05)$ by Kaplan-Meier method.

The Kaplan-Meier analysis showed that the presence of nestin in tumoral cells significantly predicted poor prognosis at 5-years survival (Figure 2; $\mathrm{P}=0.02$ ) and with borderline significance at 10-years of survival (Figure 3 ; $\mathrm{P}=0.05$ ) in patients with $\mathrm{T} 4$ breast cancer, while after 10-years survival nestin presence lost its prognostic value $(\mathrm{P}=0.09)$. Statistical data are showed in Table 2.

\section{Discussion}

In the present study, we evaluated the distribution of nestin expression in T4 breast tumours and the impact of this protein expression as predictive and prognostic factor among patients with $\mathrm{T} 4$ breast carcinoma.

Nestin staining was interpretable in more than half of examined tumours, and its expression correlated with inflammatory and hormone receptor status.

Inflammatory breast cancer is a specific and aggressive form of LABC, characterized by an elevated metastatic and angiogenic potential, ${ }^{25}$ and by poor prognosis. ${ }^{26,27}$ It was demonstrated that IBC shows a distinct gene-expression profile compared to non-IBC..$^{19}$ In the study of Bertucci et al., as compared with the group rich in NIBC, the group of tumours rich in IBC exhibited overexpression of the basal, the immune, and the vascular gene clusters and underexpression of the luminal cluster. ${ }^{26}$ These expression changes were in agreement with the phenotypical characteristics of IBC and NIBC, and suggest that IBC is related to the basal lineage more frequently than is NIBC. ${ }^{26,27}$ The IBC cases of the present study showed a strong difference in expression of nestin compared to non-IBC, with $80 \%$ of IBC positive for nestin expression. A recent study reported co-expression of nestin and melatonin receptor 1 (MT 1) in patients with higher tumor stages (TII/III), signifying that coexpression of nestin and MT 1 may correlate with invasive breast cancer and advanced tumors. ${ }^{15}$ Lymphovascular emboli of inflammatory breast cancer, characterized by exaggerated lymphovascular invasion, express stem cell markers, including nestin. ${ }^{28,29}$ Our results confirm these data and indicate that nestin correlates with an aggressive growth phenotype. This stem cell-like phenotype, characterized by strong expression of many angiogenesis mark$\mathrm{ers}^{28}$ including nestin, may contribute to the aggressive nature of IBC by a metastatic mechanism in which an increased number of tumor vessels increases the chances for tumor cells to enter the circulation. Newly formed tumor vessels or capillaries have leaky and weak basement membranes; thus, tumor cells can penetrate these more easily than they can mature vessels.

In the current study, nestin was observed in endothelial cells of numerous microvessels in all cases. In agreement to various reports, indicating nestin as angiogenesis marker for proliferating endothelial cells in many cancer tissues, ${ }^{10,30-32}$ our results show nestin staining as

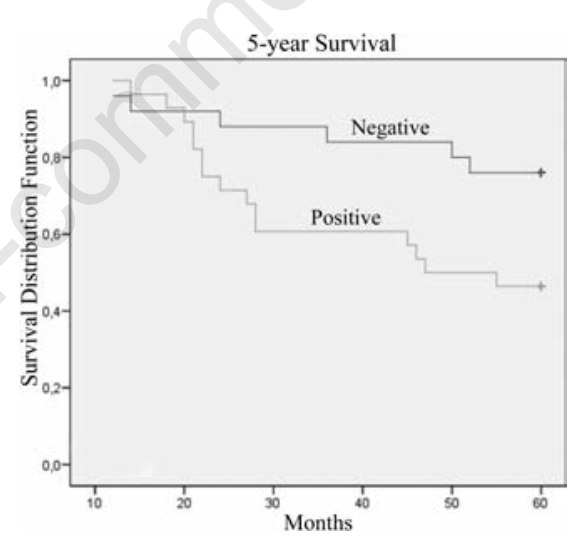

Figure 2. Kaplan-Meier's 5-year survival curves according to immunoreactivity for nestin protein of patients with $\mathrm{T} 4$ breast cancer $(P=0.02)$. indicator of newly formed endothelial cells and of an remarkable involvement of this protein in angiogenesis and vasculogenesis of breast cancer.

Recent studies evaluated nestin distribution in different receptor phenotypes of T1, T2 and T3 breast tumours. Nestin was found highly expressed in basal breast cancer subtype (ER $\alpha-/ P R-/ H e r 2-)$ but not in the Her2 subtype (ER $\alpha$-/PR-/Her2+) or luminal epithelial phenotype $(\mathrm{ER} \alpha+/ \mathrm{PR}+) .{ }^{16}$ According these data, a recent study showed that triple-negative breast cancers have higher expression rates for nestin than other breast cancers. ${ }^{18}$ Another study has reported significantly high nestin expression in basal-like and triple negative breast cancers in a cohort of patients with invasive breast cancer treated with surgery followed by anthracycline-based chemotherapy. ${ }^{17}$ In the present study, nestin was found preferentially expressed in triple negative breast tumours and correlated with lack of ER and PR, while it was poorly expressed in luminal phenotypes. These data support precedent findings and, although the involvement of nestin in molecular mechanisms of triple negative is still unclear, they indicate that nestin may be a selective marker of triple negative phenotype and the basal breast cancer subtype, that display an aggressive growth and have a poor prognosis in stage IIIB T4 locally advanced breast tumours.

Breast tumours are histologically complex

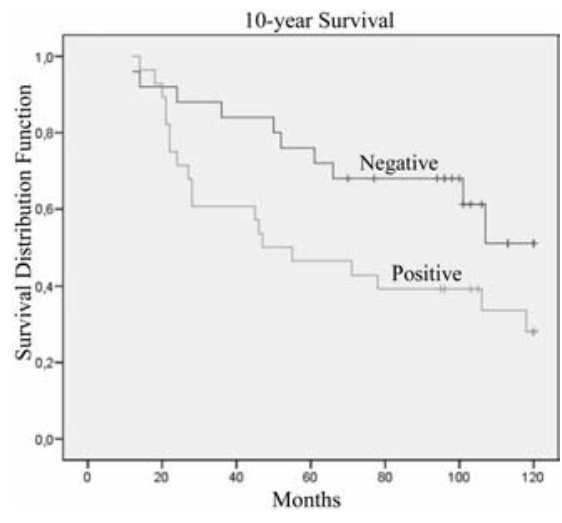

Figure 3. Kaplan-Meier's 10-year survival curves according to immunoreactivity for nestin protein of patients with $\mathrm{T} 4$ breast cancer $(\mathbf{P}=\mathbf{0 . 0 5})$.

Table 2. Estimated 5- and 10-year survival rates for T4 breast cancer patients with different nestin expression

\begin{tabular}{lcccccc} 
& Patients & Events 5-years & \% 5-year survival (SE) & P* & Events 10-years & \% 10-year survival (SE) \\
Nestin & & & & 0.02 & 0.05 \\
Negative & 25 & 6 & $76.0(8.5)$ & & 10 & $51.0(12.8)$ \\
\hline Positive & 28 & 15 & $46.4(9.4)$ & 19 & $28.1(9.4)$ \\
\hline
\end{tabular}

*Log-rank-test. 
tissues, containing a variety of cell types in addition to the carcinoma cells, such as endothelial cells, adipose-enriched/normal breast cells, B, T lymphocytes, macrophages, and stromal cells. In our study, in peritumoral stroma, cells with fibroblast morphology were positive for nestin. This is an important finding, since it has become increasingly evident that epithelial-stromal interactions are crucial to tumor development and fibroblasts in the tumor microenvironment are involved in angiogenesis, growth and invasion. ${ }^{33-35}$

Furthermore, nestin expression has been associated with shorter survival and shown to be an independent prognostic factor of breast cancer. ${ }^{18}$ Our findings indicated that this subset of T4 breast cancer patients with nestin expression in primary tumour tissues presented a worse overall 5- and 10-years survival rate respect to cases without nestin expression. Since an increased expression of nestin in tumour tissues has been already demonstrated to correlate with a poor clinical outcome in a variety of malignancies, ${ }^{28}$ our results clearly indicated an analogous significant impact on prognosis of such a molecular alteration among T4 breast cancer patients. In fact, although the role of nestin in breast cancer has not been well characterized, there is evidence to suggest that this protein may play a role in the regulation of mitosis ${ }^{16,36,37}$ and tumour invasiveness. ${ }^{38}$ Among histologicalclinical variables evaluated, only triple negative status and nodal involvement, and clinical response after primary chemotherapy were significantly correlated with overall survival. The role of these variables as prognostic and predictive factors is already well defined, however, the assessment of additional biomarkers strictly related to tumour cell biology, as nestin, could improve the accuracy of diagnosis or risk assessment to guiding selection of optimal therapeutic interventions in support of the paradigm shift towards more personalized medicine.

In our study, nestin expression doesn't seem to be significantly correlated with response to primary chemotherapy; however, note worthy is that no change in nestin expression was found between core-needle aspirates and surgical specimens of the same patient.

In summary, our findings show that nestin is consistently expressed in triple-negative and in IBC subgroups of T4 breast cancer. Nestin expression may characterize tumors with an aggressive clinical behavior, suggesting that the presence of nestin in tumoral cells and vessels can be considered an important factor that leads to a poor prognosis. To validate the incorporation of nestin as marker for management of these tumours, further large prospective studies are awaited. Improved understanding of the etiology of these tumours may help to identify selective markers and therapeutic targets that will improve detection, diagnosis, and treatment of breast carcinomas.

\section{References}

1. Edge SB, Byrd DR, Compton CC, Fritz AG, Greene FL, Trotti A. Breast. In: AJCC Cancer Staging Manual, 7th ed., pp 347-76. New York, Springer, 2010.

2. Sobin LH, Gospodarowicz MK, Wittekind C, International Union against Cancer. TNM Classification of Malignant Tumors, 7th ed. Hoboken, Wiley-Blackwell, 2009.

3. Woodward WA, Strom EA, Tucker SL, McNeese MD, Perkins GH, Schechter Nr, et al. Changes in the 2003 American Joint Committee on Cancer staging for breast cancer dramatically affect stage-specific survival. J Clin Oncol 2003;21:3244-8.

4. Subramaniam DS, Isaacs C. Utilizing prognostic and predictive factors in breast cancer. Curr Treat Options Oncol 2005;6:14759.

5. Hayes DF. Prognostic and predictive factors revisited. Breast 2005;14:493-9.

6. Singh LC, Chakraborty A, Mishra AK, Devi TR, Sugandhi N, Chintamani C, et al. Study on predictive role of AR and EGFR family genes with response to neoadjuvant chemotherapy in locally advanced breast cancer in Indian women. Med Oncol 2011 [Epub ahead of print].

7. Lendahl U, Zimmerman LB, McKay RD. CNS stem cells express a new class of intermediate filament protein. Cell 1990;60:585-95.

8. Zimmerman L, Parr B, Lendahl U, Cunningham M, McKay R, Gavin B, et al. Independent regulatory elements in the nestin gene direct transgene expression to neuron specific stem cells or muscle precursors. Neuron 1994;12:11-24.

9. Strojnik T, Rosland GV, Sakariassen PO, Kavalar R, Lah T. Neural stem cell markers, nestin and musashi proteins, in the progression of human glioma: correlation of nestin with prognosis of patient survival. Surg Neurol 2007;68:133-43.

10. Piras F, Perra MT, Murtas D, Minerba L, Floris C, Maxia C, et al. The stem cell marker nestin predicts poor prognosis in human melanoma. Oncol Rep 2010;23:1724.

11. Ehrmann J, Kolar Z, Mokry J. Nestin as a diagnostic and prognostic marker: immunohistochemical analysis of its expression in different tumours. $\mathbf{J}$ Clin Pathol 2005;58:222-3.

12. Teranishi N, Naito Z, Ishiwata T, Tanaka N, Furukawa K, Seya T, et al. Identification of neovasculature using nestin in colorectal cancer. Int J Oncol 2007;30:593-603.

13. Kleeberger W, Bova GS, Nielsen ME, Herawi M, Chuang AY, Epstein JI, et al. Roles for the stem cell associated intermediate filament Nestin in prostate cancer migration and metastasis. Cancer Res 2007;67:9199-206.

14. Kawamoto M, Ishiwata T, Cho K, Uchida E, Korc M, Naito Z, et al. Nestin expression correlates with nerve and retroperitoneal tissue invasion in pancreatic cancer. Hum Pathol 2009;40:189-98.

15. Rogelsperger 0, Ekmekcioglu C, Jager W, Klimpfinger M, Konigsberg R, Krenbek D, et al. Coexpression of the melatonin receptor 1 and nestin in human breast cancer specimens. J Pineal Res 2009;46:422-32.

16. Li H, Cherukuri P, Li N, Cowling V, Spinella $M$, Cole M, et al. Nestin is expressed in the basal/myoepithelial layer of the mammary gland and is a selective marker of basal epithelial breast tumors. Cancer Res 2007;67:501-10.

17. Parry S, Savage K, Marchiò C, Reis-Filho JS. Nestin is expressed in basal-like and triple negative breast cancers. J Clin Pathol 2008;61:1045-50.

18. Liu C, Chen B, Zhu J, Zhang R, Yao F, Jin $\mathrm{F}$, et al. Clinical implications for nestin protein expression in breast cancer. Cancer Sci 2010;10:815-9.

19. Van Laere $S$, Van der Auwera I, Van den Eynden G, Van Hummelen P, Van Dam P, Van Marck E, et al. Distinct molecular phenotype of inflammatory breast cancer compared to non-inflammatory breast cancer using Affymetrix-based genome-wide gene-expression analysis. $\mathrm{Br} \mathrm{J}$ Cancer 2007;97:1165-74.

20. Massidda B, Sini M, Budroni M, Atzori F, Deidda M, Pusceddu V, et al. Molecular alterations in key-regulator genes among patients with T4 breast carcinoma. BMC Cancer 2010;10:458.

21. Ionta MT, Perra MT, Atzori F, Maxia C, Pusceddu V, Demurtas P, at al. Long-term maintenance of prognostic value of survivin and its relationship with p53 in T4 breast cancer patients. Exp Ther Med 2010;1:59-64.

22. Horii R, Akiyama F, Ito $\mathrm{Y}$, Iwase $\mathrm{T}$. Assessment of hormone receptor status in breast cancer. Pathol Int 2007;57:784-90.

23. Hayward JL, Carbone PP, Heusen JC, Kumaoka S, Segaloff A, Rubens RD. Assessment of response to therapy in advanced breast cancer. Br J Cancer 1977;35:292-8.

24. Sataloff DM, Mason BA, Prestipino AJ, Seinige UL, Lieber CP, Baloch Z. Pathologic response to induction chemotherapy in locally advanced carcino- 
ma of the breast: a determinant of outcome. J Am Coll Surg 1995;180:297-306.

25. Van der Auwera I, Van Laere SJ, Van den Eynden GG, Benoy I, van Dam P, Colpaert $\mathrm{CG}$, et al. Increased angiogenesis and lymphangiogenesis in inflammatory versus noninflammatory breast cancer by realtime reverse transcriptase-PCR gene expression quantification. Clin Cancer Res 2004;10:7965-71.

26. Bertucci F, Finetti P, Rougemont J, Charafe-Jauffret E, Nasser V, Loriod B, et al. Gene expression profiling for molecular characterization of inflammatory breast cancer and prediction of response to chemotherapy. Cancer Res 2004;64:855865 .

27. Bertucci F, Finetti P, Birnbaum D, Viens P. Gene expression profiling of inflammatory breast cancer. Cancer 2010;116:2783-93.

28. Xiao Y, Ye Y, Yearsley K, Jones S, Barsky SH. The lymphovascular embolus of inflammatory breast cancer expresses a stem cell-like phenotype. Am J Pathol 2008;173: 561-4.

29. Ishiwata T, Matsuda Y, Naito Z. Nestin in gastrointestinal and other cancers: effects on cells and tumor angiogenesis. World $\mathrm{J}$ Gastroenterol 2011;17:409-18.

30. Teranishi N, Naito Z, Ishiwata T, Tanaka N, Furukawa K, Seya T, et al. Identification of neovasculature using nestin in colorectal cancer. Int J Oncol 2007;3:593-603.

31. Mokrý J, Cízková D, Filip S, Ehrmann J, Osterreicher J, Kolár Z, et al. Nestin expression by newly formed human blood vessels. Stem Cells Dev 2004;13:658-64.

32. Mokrý J, Cízková D, Ehrmann J, Stanislav F, Kolár Z. Expression of intermediate filament nestin in vascular endothelium. Folia Histochem Cyto 2008;46:90.

33. Tlsty TD, Coussens LM. Tumor stroma and regulation of cancer development. Annu Rev Pathol 2006;1:119.

34. West RB, van de Rijn M. Experimental approaches to the study of cancer-stroma interactions: recent findings suggest a pivotal role for stroma in carcinogenesis. Lab Invest 2007;87:967.

35. Sellheyer K, Krahl D. Does the peritumoral stroma of basal cell carcinoma recapitulate the follicular connective tissue sheath? J Cutan Pathol 2011;38:551-9.

36. Chou YH, Khuon S, Herrmann H, Goldman RD. Nestin promotes the phosphorylation dependent disassembly of vimentin intermediate filaments during mitosis. Mol Biol Cell 2003;14:1468-78.

37. Sahlgren CM, Mikhailov A, Hellman J, Chou YH, Lendahl U, Goldman RD, et al. Mitotic reorganization of the intermediate filament protein nestin involves phosphorylation by cdc2 kinase. J Biol Chem 2001;276:16456-63.

38. Yang XH, Wu QL, Yu XB, Xu CX, Ma BF, Zhang XM, et al. Nestin expression in different tumours and its relevance to malignant grade. J Clin Pathol 2008;61:467-73. 